\title{
Caregivers Feeding Styles for Children 6-20 Months of Age in Rural Areas Wonosobo District Central Java Indonesia
}

\author{
Hadi Ashar ${ }^{1, *}$, Ina Kusrini ${ }^{2}$, Leny Latifah ${ }^{3}$ and Dyah Yunitawati ${ }^{4}$ \\ 1,2,3,4 Magelang Health Research and Development Center, Central Java Indonesia \\ *Corresponding author. Email: hdi.gaki@gmail.com
}

\begin{abstract}
Caregivers feeding style is one of the efforts in preventing malnutrition. It not only fills the nutrition needs to grow but also, psychologically, fills the affection that will support the child's growth and development. The purpose of this study is to know the feeding style to the children and the influencing factors. This article is a further analysis based on research data conducted in 2019, a selected sub-district in Wonosobo, Central Java with a cross-sectional study design. A total of 402 mothers participated in this study. The participating mothers had to meet certain criteria, such as having a child whose age was between 6 and 20 months, the care was carried out by the biological mother. Caregiver's Feeding Styles Questionnaire was applied to collect data. Chi Square and logistic regression were employed to analyse the data. The study showed that caregiver feeding style was classified as follows: authoritarian type $59.0 \%$; democratic $33.6 \%$; permissive $3.7 \%$ and uninvolved $3.7 \%$. There was a significant relationship between maternal educations, the child's age and caregiver feeding style. The result of logistic regression test showed that maternal education was related to the parenting style. Mother with high education was considered to have a democratic parenting with OR score 3.4. After being controlled with the child's age within the category more than 12 months, in the age category for more than 12 months, it showed that the OR score was 1.9. This can be concluded that the authoritarian (non-adaptive) style was the most commonly feeding type found in this study. The influencing factor to the caregiver feeding style is the maternal education and the children's age. Increasing knowledge with attention, guidance and education to mothers are imperative in changing / improving good parenting patterns as a compensation for the lack of formal mother education.
\end{abstract}

Keywords: Caregiver Feeding Style.

\section{INTRODUCTION}

A child whose age is less than two years is prone to suffer from malnutrition. This can cause growth and development-related disorders [1]. Some factors can affect children's growth and development, directly or indirectly. The directly influencing factors relate to care given by mothers to their children. According to UNICEF, three determinant factors directly contribute to children's growth and development, namely: nutritional intake, patterns of care given by mothers to children and health status/morbidity of children, including access to health services and a clean environment [2]. UNICEF has said that the imbalance of these factors will influence to the children's growth and development. Beside the three factors, some categories have impact indirectly, such as education, job, socio-economy, attitude of mother and environmental health/disease.

Mother's care to her children is an interaction between a mother/caregiver to the children. Mother will be responsible for meeting children's needs to support their growth and development. With her instinct, mother will do those things and become her responsibility. She will give care that suits to her ability. (But in this case, the care given is not only filling the nutritional needs to grow and develop). The more important than this is the loving care to meet psychological needs that will support the children's development. It will go hand in hand, and be related to each other. The good caregiver feeding style, psychologically, will increase the children's food intake. The increasing food intake will make children have their rapid growth. The care of a mother becomes 
the important thing in increasing growth and development. If a mother does not pay attention in giving care, the nutritional intake will not be fulfilled and the children's health will be disturbed. It is called the imbalance of the three factors associated with child growth and development. The factors of parenting will affect to the nutrition intake and children's health.

According to Baumrind 1970 that was developed by Maccoby and Martin in 1984 in Christin and Seher [3] said that the caregiver feeding is categorized into four, namely: Authoritative/ democratic; Authoritarian; Indulgent/Permissive; and Neglectful/ Uninvolved. A democratic style is a parenting style with a balance between demandingness and responsiveness. A mother always has control in caring and responds quickly to what happened to the children. An authoritarian style is a strict style of parenting; she always has control to her child's attitude with any restrictions ignoring their opinion. A permissive style is when a mother lets her children to do everything without any restrictions (indulging), meanwhile the uninvolved style is a parenting with low demandingness and responsiveness or hands off[3].

The caregiving and feeding style to the children done by the mother can be varied, depend on the knowledge, ability and capability of the mother/ caregiver, as like stated by Jansen et al [4], that caregiving and feeding practices given by mother/caregiver are affected by the education and economy level. The poverty level in Indonesia still becomes a problem, especially in the rural area. The results of the 2012 Indonesian Demographic and Health Survey shows that there are $13.6 \%$ women in the rural who do not attend school and $33.5 \%$ is in lowest wealth quintile compared to urban areas at $6.4 \%$ [5]. This problem will be a trigger factor to other problems that will impact to the health of the family.

Parenting becomes a problem that will appear related to the low education and the economic limitation. With the limited education and economy, a mother will be difficult to give care and get adequate health services. As a result, the health status of children will decline. The result of a study stated that the suitable care will have positive influence to the children growth[6]. What is meant in this case is the care given not only accompanying children to play and giving food intake. The given care becomes a means of interaction, communication, and giving affection from a mother/caregiver to the children. A child will feel comfortable and peace if they are with a mother who gives a suitable care. It can be as important as the provision of complementary foods to meet the growth and development needs of children. With a good care, it will increase the food intake, and the provision of complementary foods with a good nutrition source will increase the nutritional status of the children.
The 2012 study result in Ethiopia to children in 6 to 23 months concluded that children less than 2 years old is an early age to give additional food, it is suggested to see the factors that influence the feeding style and care given practice[7]. Identifying the existing factors will be very useful to specify the parenting style. These factors will be given as an intervention effort to obtain the suitable care attitude and practice in feeding. The attitude of a mother including caregiving will be affected by her knowledge and experience. It will contribute to the caregiving[8].

Based on the explanation before, the purpose of this study is to identify the caregivers feeding style and its affecting factors.

\section{METHOD}

This article was a further analysis from a research in 2019 in Wonosobo, Central Java. It uses CrossSectional Study. The population was 450 children aged between 6 and 20 months in one sub-district in Wonosobo Regency. The sample criteria was that biological mother had to provide care for her child. A total of 402 mothers as the samples in this study.

Individual questionnaire was implemented to collect mother's and child's characteristics. The caregiver's feeding style was measured using Caregiver's Feeding Styles Questionnaire (CFSQ) by a psychologist. According to Baumrind 1970 developed by Maccoby and Martin in 1984, the CFSQ is a questionnaire containing 19 items measured through a series of questions, and scored on a fivepoint scale (never, rarely, sometimes, often and always). The measurement of CFSQ showed the reliability of containing questions on the basis of the level of mother / caregiver demandingness and responsiveness to children during feeding[9], and then categorised into 4 types namely: democratic (high demandingness and responsiveness), authoritarian (high demandingness and low responsiveness), permissive (low demandingness and high responsiveness), or uninvolved (low demandingness and responsiveness)[10].

The analysis presented in this essay is a univariate analysis conducted to know the characteristic of mother and children. The Chi-square analysis was used to identify the relation of the affecting factors. The independent variables in this study were age, mother's education, job and the child's age. The dependent variable was feeding style. The feeding style was categorised into adaptive style (democratic) and non-adaptive style (authoritarian, permissive and uninvolved). 


\section{RESULT}

Table 1 The characteristic of mother and children

\begin{tabular}{llc}
\hline Variable & Category & $\mathrm{N}(\%)$ \\
\hline Mother & & \\
\hline Age & $<20$ years old & $16(4.0)$ \\
& $>$ /=20 years old & $386(96.0)$ \\
Education & Low & $379(94.3)$ \\
& High & $23(5.7)$ \\
Job & Unemployed & $231(57.5)$ \\
& Employee & $171(42.5)$ \\
Caregiving & Democratic & $135(33.6)$ \\
& Authoritarian & $237(59.0)$ \\
& Permissive & $15(3.7)$ \\
& Uninvolved & $15(3.7)$ \\
\hline Children & & \\
\hline Age & $<12$ months & $207(51.5)$ \\
& $>/=12$ months & $195(48.5)$ \\
Gender & Female & $183(45.5)$ \\
& Male & $219(54.5)$ \\
\hline
\end{tabular}

The characteristic of children based on the age can be divided into the baby age (less than 12 months) and 12 months or more children with almost equal distribution, as well as the gender.

Healthy and nutritious feeding is the general thing that happened in every mother and children. As like stated in the Maternal and Child Health Handbook, baby and toddler should receive adequate nutrition intakes, which include exclusive breastfeeding an adequate complementary food. But caregiving and feeding style given by every mother are varied. The care given by mother to her children will reflect her knowledge, attitude and behaviour. Mother's caregiving to her child will affect the child's growth and development

Parenting in early age is the critical care in fulfilling breast milk and complementary food. Improper care will affect their growth and development[11]. Facing this case, with her knowledge and skill, it is expected that a mother can give suitable care to support child's further growth and development[12]. It means that the proper care can improve the nutritional status and health of children[13][14]. Some research results show the importance of giving proper caregiving to increase the child's growth and development. Mothers living in urban area may be able to support their children's growth and development due to their adequate socioeconomic conditions. In contrast, limited supportive resources may bring complex problem for mothers to care their children. In urban area with adequate education and supported by adequate socioeconomic conditions, it is possible that they have realized. But in rural areas where everything is less supportive, it will become a complex problem, and need specific and intensive handling

Mother characteristics in this study illustrate that almost all mothers belong to the reproductive age group. This means that from a medical perspective, women of reproductive age, namely women over 20 years of age, are a safe age for reproduction, undergoing pregnancy and facing childbirth. Physiologically, the mother's reproductive organs are ready and functioning properly to do this. The reproductive age group is expected to be able to care for and provide good care for children, fulfill the need for good nutrition, the need for health services if needed and foster a loving relationship between mothers and children. The age factor will support physiologically and psychologically in increasing the optimal growth and development of children.

Seeing from the educational factor, almost all mothers have low education, namely mothers who have never attended school, graduated from elementary school or graduated from junior high school and $57.5 \%$ of mothers do not have permanent jobs (do not work). Education is still a problem, especially in rural areas in Indonesia. The existing educational facilities and infrastructure supports are much different from those in urban areas. This factor contributes to the high dropout rate which causes lower education in rural areas compared to urban areas, in addition to demographic and socio-economic factors[5].

More than half of the care giving mother to child applies authoritarian parenting, which has high demandingness, but low responsiveness, only about a third doing it democratically and the rest are permissive and uninvolved. This care illustrates how mothers interact with their children in everyday life, by characterising the mother's behaviour to do demandingness and responsiveness. The care provided by mothers reflected their knowledge and experience of childcare, the demands and responses to parenting style that the mother does become a style for each mother that will affect the growth and development of the child. Parenting style still a problem that mothers do not necessarily realize that what mothers do in their care style will affect the growth and development of their children in the future. Several studies have shown that parenting has an impact on children's growth and development[14].

Democratic feeding style was applied by $33.6 \%$ mothers. This style is used to encourage children's independency, place the limitations as their considerations (demandingness), discuss/make verbal contact, and show affection. A mother gives high responses to the child's condition. High responsiveness is very important in the feeding style[15]. The responsive attitudes given by mothers are characterised by actively helping, physically and 
verbally during feeding time, engaging through roleplaying, persevering and always making communication as one of the positive feeding strategy[16]. The democratic feeding style increases children's food intake. Other studies state that democratic feeding style is highly significant to food quality compared to the authoritarian style [10],[17]. Further, studies in poor and developing country concludes that an active and responsive feeding style have positive impact to energy intake [18],[19]. The democratic feeding style is a proper care to increase creativity in every stage of development and increase the food intake.

This study showed that $3.7 \%$ mothers practiced permissive feeding style. A permissive feeding style is characterised by showing gratification to children with few limitations and being permissive. the style of mother indulging her children, which the mother always pays attention to her children but only makes. She lets them do whatever they want. Her decision is too soft by letting them to do what they like and not giving them restrictions to their behaviour[3] (democratic) and non-adaptive (authoritarian, permissive, and uninvolved). The result of analysis shows that there is a relationship between the characteristic of mother and care, which there is a significant relationship between maternal education and children age with the mother care.

Education is related to the knowledge, attitude and behaviour that will form a characteristic of mother. She will do a care style depending on their capability. The maternal education is contributed to the care given. Less education / knowledge tends to behave in an authoritarian manner in care style. The mother will demonstrate a parenting style that is demanding and controlling. Mothers with basic education were $60.2 \%$ with an authoritarian style and $30.6 \%$ were democratic. Mothers with higher education tend to be more democratic. $39.1 \%$ with an authoritarian style and $60.9 \%$ democratic. These findings indicate that there is a huge impact on maternal education on their parenting patterns.

Table 2 showed that the age of the child had an effect on the pattern of care given by the mother.

Table 2. Relationship between mother and children with the caregivers feeding style

\begin{tabular}{|c|c|c|c|c|}
\hline \multirow{2}{*}{ Variable } & \multirow{2}{*}{ Category } & \multicolumn{2}{|c|}{ Parenting Style } & \multirow{2}{*}{$P$ value } \\
\hline & & $\begin{array}{c}\text { Adaptive } \\
\text { (Democratic) } \\
\mathrm{n}(\%)\end{array}$ & $\begin{array}{c}\text { Non-adaptive } \\
\text { (authoritarian +permissive } \\
\text { +uninvolved) } \\
\mathrm{n}(\%)\end{array}$ & \\
\hline \multirow[t]{2}{*}{ Mother's age } & $<20$ years old & $4(25.0)$ & $12(75.0)$ & \multirow[t]{2}{*}{0.458} \\
\hline & $>20$ years old & $131(33.9)$ & $225(66.1)$ & \\
\hline \multirow{2}{*}{ Education } & Basic & $121(31.9)$ & $258(68.1)$ & \multirow[t]{2}{*}{0.006} \\
\hline & High & $14(60.9)$ & $9(39.1)$ & \\
\hline \multirow[t]{2}{*}{ Job status } & Unemployed & $78(33.8)$ & $153(66.2)$ & \multirow[t]{2}{*}{0.928} \\
\hline & Employee & $57(33.3)$ & $114(66.7)$ & \\
\hline \multirow[t]{2}{*}{ Child's age } & $<12$ months & $55(26.6)$ & $152(73.4)$ & \multirow[t]{2}{*}{0.002} \\
\hline & $>/=12$ months & $80(41.0)$ & $115(59.0)$ & \\
\hline
\end{tabular}

This style is characterised by mothers' unresponsiveness to their children's needs. Mothers may only provide children's basic needs without giving proper care which a care when a mother is not involved in the child life. She does not limit or give response to the children, or it can be said that she lets her children do everything. [3].

In the result of Chi Square test, the relationship between the characteristic of mother with the feeding style to the children shows that there is a significant relationship between the education of mother and the feeding style to the children. The characteristic of children based on age have a significant relationship to the feeding style.

In doing the relation analysis in this study, further, the writer divides them into adaptive feeding style
Mothers were attentive to children aged more than one year old compared to younger children. The age of children who were more than one year old shows more clearly the response to care given. The mother will pay more attention to the response of the child compared to younger children. Mother's response is obvious when mother's knowledge of how to care for children is sufficient. This finding aligns with a study by Hodges et al [11] that finds a relationship between responsiveness and maternal educational background, age of children, and aspects of child feeding, including the duration of the mother in breastfeeding[11]. 
Adaptive (democratic) parenting style from mothers to children is the right balance between setting restrictions and the response given. This parenting style encourages children to think in real terms, expects maturity and allows children to make decision making, explores every developmental stage for optimal child development[10]. Adaptive (democratic) parenting is a good choice of parenting for children's creativity, fostering loving relationships for children for optimal child development. changing mother's behaviour. This can be a breakthrough in changing / improving better parenting styles for mothers to children (adaptive / democratic). This breakthrough can be a compensation for the lack of formal education for mothers in rural areas

For conclusion, authoritarian (non-adaptive) feeding style was the type most commonly practiced by mothers in this study. Mother's education level and child's age of under-five. Mothers who were highly educated tend to practice democratic parenting.

Table 3. Result of logistic regression test between mother and children with the feeding style

\begin{tabular}{lcccccccc}
\hline & & & & & & & \multicolumn{3}{c}{$\begin{array}{c}\text { 95,0\% C.I.for } \\
\text { EXP(B) }\end{array}$} \\
\cline { 5 - 10 } \multicolumn{1}{c}{ Variable } & B & S.E. & Wald & Df & Sig. & Exp(B) & Lower & Upper \\
\hline Education of mother & 1.237 & 0.448 & 7.632 & 1 & 0.006 & 3.444 & 1.432 & 8.281 \\
Child's age & 0.670 & 0.217 & 9.538 & 1 & 0,002 & 1.954 & 1.277 & 2.990 \\
Constant & -1.103 & 0.163 & 45.923 & 1 & 0,000 & 0.332 & & \\
\hline
\end{tabular}

Table 3 showed that the result of logistic regression test shows that the education of mother is related to the feeding style. A highly educated mother (Senior High School and University Graduator) considered having democratic parenting with OR score 3.4. After it was controlled by the children age more than 12 months, it shows the OR score 1.9. This is a challenge, with various educational and socio-economic backgrounds in rural areas that it is necessary to have a new breakthrough, so that the pattern of care given will support the nutritional status, creativity and optimal development of children. Other studies stated that the emotional relationship between both psychological and care styles will affect food intake[20]. Meanwhile, the mother's feeding style contributes to the overall $\operatorname{diet}[10][21]$.

These findings highlighted that mothers' characteristics became factors related to child feeding style. Mothers living in rural areas with average basic experienced a challenge to educate and assist them to practice well feeding style to support their children's growth and development. Mothers in rural areas are in need of attention, guidance, training and education related to giving appropriate caregiving on how good the caregiving is. It is argued that mothers with basic educational background tend to develop a nonadaptive care style of feeding their children. Therefore, increased knowledge and skills in caregiving is expected to be effective in changing maternal parenting style in rural areas. Education is primarily aimed at mothers with a basic educational background, which has a major contribution to the non-adaptive care style of feeding children. Increased knowledge and skills in care given by means of training guidance are expected to be effective in
Increasing knowledge with attention, guidance and education to mothers are needed in changing / improving good parenting patterns as a compensation for the lack of formal mother education.

\section{CONCLUSION}

This study found that the authoritarian (non-adaptive) style was the most commonly feeding type found in this study. Maternal education and the children's age were the influencing factor to the caregiver feeding style. Increasing knowledge with attention, guidance and education to mothers are imperative in changing / improving good parenting patterns as a compensation for the lack of formal mother education.

This study has limitations, such as this study only covers certain age group. Further study is needed to include a more diverse population age using consistent methodological and objective measures.

\section{AUTHORS' CONTRIBUTIONS}

Hadi Ashar (HA): Conceptualising, drafting and analysing of data; Ina Kusrini (IK): Revising the manuscript and analysing; Dyah Yunitawati (DY): Collecting and interpreting data; Leny Latifah (LL): Collecting, categories and analysing data of CFSQ

\section{ACKNOWLEDGMENTS}

The author thanks for Magelang Health Research and Development Center Central Java Indonesia and the research team who support this study. 


\section{REFERENCES}

[1] Balitbangkes, "Laporan Nasional Riskesdas 2018," 2018. doi: 10.1017/CBO9781107415324.004.

[2] UNICEF, “Annual Report 2009,” 2009.

[3] L. Christin and M. Seher, "Parent-Child Interaction During Feeding," Today's Dietitian, 2011.

[4] P. W. Jansen et al., "Children's Eating Behavior, Feeding Practices of Parents and Weight Problems in Early Childhood: Results from the Population-based Generation R Study," Int. J. Behav. Nutr. Phys. Act., vol. 9, no. 1, p. 1, 2012, doi: 10.1186/1479-5868-9-130.

[5] Badan Pusat Statistik, "Survei Demografi dan Kesehatan Indonesia 2012," 2012. doi: 10.1111/j.1471-0528.2007.01580.x.

[6] F. E.Aboud, D. R.Singla, M. I. Nahil, and Ivelina Borisova, "Effectiveness of a parenting program in Bangladesh to address early childhood health, growth and development,"Soc. Sci. Med., vol. 97, 2013, doi: https://doi.org/10.1016/j.socscimed.2013.06.020

[7] M. Wondafrash, T. Amsalu, and M. Woldie, "Feeding Styles of Caregivers of Children 6-23 Months of Age in Derashe Special District, Southern Ethiopia," BMC Public Health, vol. 12, no. 1, p. 235, 2012, doi: 10.1186/1471-2458-12235.

[8] H. Ashar, I. Kusrini, and L. Latifah, "Intervention Strategy to Increase Growth and Development for Stunted Children Under Two Years with Developmental Delay," Eur. J. Mol. Clin. Med., vol. 07, no. 10, pp. 280-292, 2020.

[9] M. de F. Ferreira et al., "Cross-cultural Adaptation of the Brazilian Portuguese Version of the Caregiver's Feeding Styles Questionnaire," Int. J. Environ. Res. Public Health, vol. 17, no. 16, pp. 1-16, 2020, doi: 10.3390/ijerph17165814.

[10] K. R. Arlinghaus et al., "Authoritative Parent Feeding Style is Associated with Better Child Dietary Quality at Dinner Among Low-income Minority Families," Am. J. Clin. Nutr., vol. 108, no. 4, pp. 730-736, 2018, doi: 10.1093/ajcn/nqy142.

[11] E. A. Hodges, S. L. Johnson, S. O.Hughes, J. M.Hopkinson, N. F. Butte, and Jennifer o Fisher, "Development of the Responsiveness to Child Feeding Cues scale," Appetite, vol. 65, no. 1, pp. 210-219, 2013, doi: https://doi.org/10.1016/j.appet.2013.02.010.
[12] D. Arikpo, E. S. Edet, Chibuzor, M. T. Odey, F. Caldwell, and D. M, "Educational Interventions for Improving Primary Caregiver Complementary Feeding Practices for Children Aged 24 Months and Under," Cochrane Database of Systematic Reviews 2018, vol. 5. 2018, doi: 10.1002/14651858.CD011768.pub2.

[13] M. K. Spill et al., "Caregiver Feeding Practices and Child Weight Outcomes," Am. J. Clin. Nutr., vol. 109, no. Supplement_1, pp. 990S-1002S, 2019, doi: https://doi.org/10.1093/ajen/nqy276.

[14] K. M. Hurley, M. B. Cross, and S. O. Hughes, “A Systematic Review of Responsive Feeding and Child Obesity in High-Income Countries 1-3," J. Nutr., vol. 141, pp. 495-501, 2011, doi: 10.3945/jn.110.130047.

[15] G. A. P. Silva, K. A. O. Costa, and E. R. J. Giugliani, "Infant Feeding: Beyond the Nutritional Aspects," J. Pediatr. (Rio. J)., vol. 92, no. 3, pp. S2-S7, 2016, doi: 10.1016/j.jped.2016.02.006.

[16] P. B. Ha et al., "Caregiver Styles of Feeding and Child Acceptance of Food in Rural Vietnam," Food Nutr. Bull., vol. 23, no. 4 SUPP, pp. 95100, 2002, doi: 10.1177/15648265020234s213.

[17] K. Baye, A. Tariku, and C. Mouquet-Rivier, "Caregiver-infant's Feeding Behaviours are Associated with Energy Intake of 9-11 Monthold Infants in Rural Ethiopia," Matern. Child Nutr., vol. 14, no. 1, pp. 1-8, 2018, doi: 10.1111/mcn.12487.

[18] M. E. Bentley, H. M. Wasser, and H. M. CreedKanashiro, "Responsive Feeding and Child Undernutrition in Low and Middle Income Countries," J. Nutr., vol. 141, pp. 502-507, 2011, doi: 10.3945/jn.110.130005.Published.

[19] H. Patrick, T. A. Nicklas, S. O. Hughes, and M. Morales, "The benefits of authoritative feeding style: caregiver feeding styles and children's food consumption patterns," Appetite, vol. 44, no. 2, pp. 245-9, 2005, doi: doi: 10.1016/j.appet.2002.07.001.

[20] K. Van Der Horst and E. F. C. Sleddens, "Parenting Styles, Feeding Styles and Food Related Parenting Practices in Relation to Toddlers' Eating Styles: A Cluster Analytic Approach," PLoS One, vol. 12, no. 5, pp. 1-16, 2017, doi: 10.1371/journal.pone.0178149.

[21] K. J. Barrett, H. M. Wasser, A. L. Thompson, and M. E. Bentley, "Contributions of Nonmaternal Caregivers to Infant Feeding in a Low-income African-American Sample," Matern. Child Nutr., vol. 14, no. 4, pp. 1-12, 2018, doi: 10.1111/mcn.12610. 